\title{
Disjunct Populations of a Locally Common North American Orchid Exhibit High Genetic Variation and Restricted Gene Flow
}

\author{
Madhav Pandey ${ }^{1,2}$, Jyotsna Sharma ${ }^{1}$ \\ ${ }^{1}$ Department of Plant and Soil Science, Texas Tech University, Lubbock, TX, USA \\ ${ }^{2}$ Current Address: Molecular Research LP, Shallowater, TX, USA \\ Email: madhav.mpandey@gmail.com,jyotsna.sharma@ttu.edu
}

Received 21 October 2015; accepted 8 December 2015; published 11 December 2015

Copyright (C) 2015 by authors and Scientific Research Publishing Inc.

This work is licensed under the Creative Commons Attribution International License (CC BY). http://creativecommons.org/licenses/by/4.0/

cC)

\begin{abstract}
Whether the persistence of natural plant populations is limited by genetic diversity, gene flow, or other ecological and evolutionary factors is an important question in plant population genetics. An assessment of the distribution of genetic variation within and among populations is thus useful for understanding broad-scale gene flow patterns in plants with diverse pollination syndromes. We studied Pogonia ophioglossoides (L.) Ker Gawl., which is self-compatible but a primarily outcrossing species in the Tribe Pogonieae in the family Orchidaceae. Using three self-developed, highly polymorphic nuclear microsatellite (simple sequence repeat, or SSR) markers and two chloroplast microsatellites, we assessed genetic variation in eight populations representing its natural distribution. Relatively high within-population genetic variation (mean An $=9.08, \mathrm{Ho}=$ 0.44 , and $\mathrm{He}=0.71$ ) was detected in P. ophioglossoides. Eleven different alleles and 13 unique haplotypes were detected for two cpDNA microsatellites. Genetic differentiation based on the hierarchical AMOVA showed that $21 \%\left(\Phi_{\mathrm{PT}}=0.21, \mathrm{P}=0.000\right)$ and $63 \%\left(\Phi_{\mathrm{PT}}=0.63, \mathrm{P}=0.000\right)$ of the nuclear and cpDNA microsatellite allelic diversity, respectively, was distributed among populations. Pairwise $F_{S T}$ values ranged from 0.041 to 0.224 and each was statistically significant at $P \leq$ 0.05. The isolation by distance estimate did not show an association between genetic differentiation and geographic distance indicating that populations were diverging independently. We documented fine-scale spatial genetic structure (FSGS) up to $40 \mathrm{~m}$ distance in Texas. Overall, gene flow across the sampled populations of $P$. ophioglossoides appears restricted, and the short-distance SGS suggests localized seed dispersal in this locally common North American terrestrial orchid.
\end{abstract}

\section{Keywords}

cpDNA, Genetic Diversity, Microsatellites, Population Differentiation 


\section{Introduction}

The Orchidaceae represents approximately $10 \%$ of the angiosperm flora on the planet [1], and a majority of the species is considered rare and uncommon in their natural habitats. The family is represented in almost all of the ecosystems across earth and displays a wide variety of ecological and biological strategies. Several species utilize deceptive and often non-rewarding pollination strategies by mimicking insects for pseudo-copulation mediated pollination, or by mimicking the scent and appearance of other organisms such as mushrooms to attract pollinators [2]. Allogamy appears to be the primary mode of sexual reproduction within the Orchidaceae, though many taxa exhibit autogamy and/or geitonogamy. Although self-compatibility is common in the Orchidaceae, it may not normally occur naturally. Regardless of the reproductive mode, low fruit-to-flower ratios are prevalent. In fact, the low reproductive success of orchids is implicated in inducing high genetic drift, which when combined with episodic selection may explain the exceptional diversification of species within the family [3]. Considering that the Orchidaceae represents complex and highly specialized ecological strategies, is represented globally, and represents a large proportion and diversity of flowering plants. It is of great interest to evolutionary biologists, biodiversity conservationists, and horticulturists alike.

One of the questions of evolutionary significance is how a species maintains the genetic variation that is considered an important prerequisite for a living organism to ensure its long-term existence. It appears that low genetic variation may be a natural phenomenon within the Orchidaceae to allow for high diversification within the family [3]. However given that there are an estimated 25,000 orchid species on the planet, this generalization likely cannot be applied to all taxa. Specific life histories, pollination syndromes, and external pressures such as habitat fragmentation, loss of pollinators, etc. significantly influence the pool of genetic resources and their distribution in any taxon [4]-[6]. In general, loss of genetic diversity due to habitat fragmentation is more severe in a historically rare species than in a common species (e.g. reviewed in [7]). However, this conception is not always true because studies have shown that common species can be equally or even more susceptible to loss of genetic variation than species with narrow distributions and isolated populations (e.g. reviewed in [6] [8] [9].

While landscape level phenomena such as gene flow between populations, genetic drift, and selection influence species-wide genetic diversity, distribution of genetic variation at micro-geographical scale within a population, known as fine-scale spatial genetic structure (FSGS) is more directly shaped by the density of populations, within-population disturbance and fragmentation, local mating and seed dispersal patterns, and asexual reproduction patterns [10]-[13]. For example, positive correlation of spatial genetic structure with the degree of fragmentation within populations has been reported [13]. Studies in the Mediterranean and East Asian terrestrial orchids revealed nearly random to significant FSGS (2 to $14 \mathrm{~m}$ ) (e.g. [14]-[17]) as a result of local seed dispersal. Such information on FSGS is useful for explaining genetic diversity patterns and for genetic resource conservation though FSGS has been examined in few orchids. Even at a larger scale, population genetic structures of relatively few orchid species have been described despite the wide array of specialized life histories and evolutionary strategies displayed in the family.

The genus Pogonia contains five species distributed primarily across the northern hemisphere. Each species within the genus is characterized by granular pollinia lacking viscidia, limited or no reward to pollinators, and presence of hairs on the labellum that visually mimic anthers and pollen [18]. It remains unknown whether these shared traits influence the genetic diversity patterns similarly across the genus. So far the population genetic structure has been reported only for the endangered East Asian Pogonia minor whereby an extremely low level of genetic diversity and significant FSGS (up to $2 \mathrm{~m}$ ) was reported by using allozyme markers [19]. In fact, a majority of the earlier orchid population genetic assessments have used either dominant or less polymorphic genetic markers such as AFLPs (Amplified Fragment Length Polymorphism) or isozymes (e.g. [20]-[24]), which limit the understanding of gene flow patterns when compared to data obtained by using highly polymorphic and co-dominant molecular markers. Pogonia ophioglossoides (L.) Ker Gawl. is the sole representative of the genus in North America and is distributed widely from east-central to eastern United States and Canada (Figure 1). The perennial herbaceous plants are typically $15-35 \mathrm{~cm}$ tall with somewhat fleshy leaves. Time to reproductive maturity is estimated to be between 2 and 3 years from seed dissemination, and relative to other terrestrial orchid taxa, germination percentages are higher [25]. Each reproductive plant generally produces a single flower between June and August. Flowers of P. ophioglossoides offer either fragrance or small amounts of nectar as reward, and bees are reported to be the main pollinators [26] [27]. The taxon is characterized as self-compatible yielding up to 95\% fruit-set following hand pollination, but natural self-mating is not likely (reviewed in [27]). 


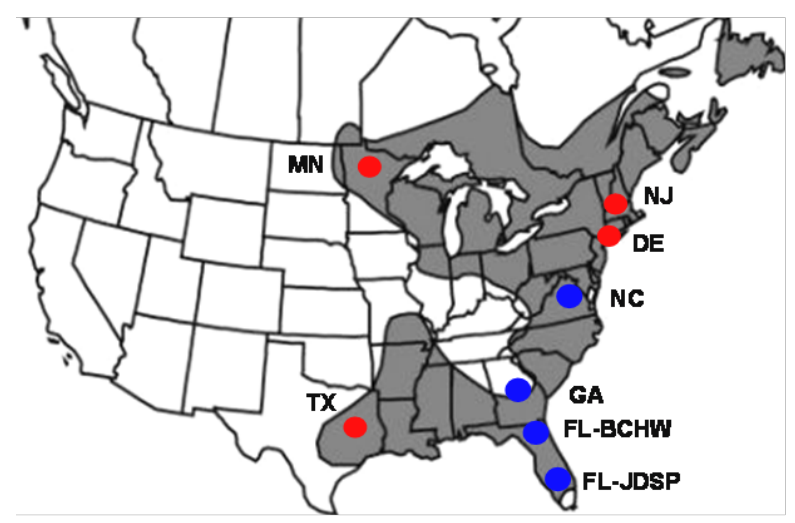

(a)

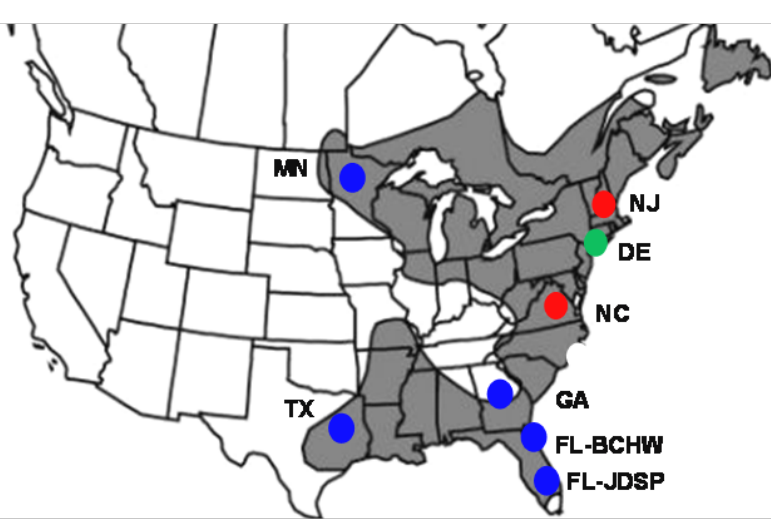

(b)

Figure 1. Maps showing the distribution range (shaded area) and experimental locations of Pogonia ophioglossoides (range map source: www.efloras.org). Colors of dots represent clustering of populations at $\mathrm{K}=2$ based on nDNA microsatellites (a) and $\mathrm{K}=3$ based on cpDNA microsatellites (b) according to the STRUCTURE analysis.

Individual populations of $P$. ophioglossoides can at times harbor up to a hundred flowering individuals, and are considered larger in comparison to those of many other North American orchids. While the US Fish and Wildlife Service considers $P$. ophioglossoides secure, several States or Provinces have designated it critically imperiled, imperiled, or vulnerable [28]. Although elucidating the genetic structure of rare plants is important, similar assessments of their more secure relatives are also essential to understand the evolutionary forces behind the spatial genetic patterns among the angiosperms. Given its wide distribution, relatively large populations, and its obligate outcrossing mating system, we expected the genetic variation within each population to be high. We further hypothesized that population differentiation will be detectable owing to the geographic separation of individual populations and lack of contiguous habitats. Finally, we expected random distribution of genotypes within an individual population considering the insect-dependent pollination and the potential for long-distance dispersal of the microscopic seeds. To investigate these hypotheses, we studied eight disjunct populations of Pogonia ophioglossoides that ranged in pair-wise geographic distances from $116 \mathrm{~km}$ to $2603 \mathrm{~km}$ to: 1) quantify genetic diversity within and among populations, and 2) assess spatial distribution of genetic variation (i.e., fine-scale spatial genetic structure) within a single population.

\section{Materials and Methods}

\subsection{Sample Collection}

Leaf tissues from 36 to 46 adult plants were collected from each of the eight sampled populations (Figure 1). In Texas, samples from 60 pairs of adults and seedlings, and 10 additional seedlings (total 130 individuals) were collected (Figure S1, Supplementary Information). One to two leaves were collected from each plant, placed in an individual plastic bag, and labeled with population name and plant number. Immediately after collection, the leaf tissues were stored in a cooler and shipped overnight to the laboratory. Geographic coordinates at a central location within each population were recorded. In Texas, geo-coordinates were recorded for each of the 60 pairs of adults and seedlings.

\subsection{DNA Extraction, Microsatellite Development and Genotyping}

Approximately $100 \mathrm{mg}$ of leaf tissue was used to extract DNA from each sampled individual (total 400 individuals) using QiagenDNeasy Plant Mini kit (Qiagen, USA) following the manufacturer's protocol. Quality and quantity of DNA was determined by using NanoDrop ND1000 (Thermo Scientific, USA). Genotyping of each individual was carried out by using three polymorphic nuclear microsatellites developed in our laboratory for $P$. ophioglossoides. A total of 69 nuclear SSRs (nSSRs) that were identified in Pandey and Sharma [29] but not tested previously for $P$. ophioglossoides were tested for this study. Of the 69 nSSRs, 14 produced bands of expected sizes, but 11 of the 14 showed either monomorphic or unscorable alleles. The remaining three nSSRs produced clear polymorphic alleles of expected sizes and were selected for genotyping. Polymerase chain reac- 
tion (PCR) amplification of the DNA samples was carried out in epGradients Master Cycler (Eppendorf, Hamburg, Germany) using a touchdown PCR program as described in Pandey and Sharma [30]. Primer sequences, range of upper and lower annealing temperatures $\left(T_{a}\right)$ for each locus and the characteristics of the SSRs is provided in Table 1. In addition to the nSSRs, we also used microsatellites representing chloroplast DNA (cpDNA) to assess within and among population genetic diversity. Based on their application in other orchid taxa (e.g., [21] [31] [32]), we tested seven published cpDNA microsatellites, i.e. rps16-1, rps16-2, accD-psa1, Cyp-2, trnStrnG, trnK-matK, and TrnL/F [31] [33]-[37] by following the protocols listed in the respective publications. Of the seven primer pairs that we tested, four (rps16-1, rps16-2, trnK-matK, TrnL/F) produced bands of expected size, but only two (trnK-matK and TrnL/F) of the four yielded polymorphisms in P. ophioglossoides. We used these two to genotype 10 samples from each of the eight populations. Genotyping was carried out by using capillary electrophoresis in Beckman GeXP (Beckman Coulter, USA). Alleles were scored based on fragment size which was determined by running the size standard along with the samples. Consistency in scoring fragment size of alleles was confirmed by running some selected samples for each locus at least three times.

\subsection{Data Analysis}

\subsubsection{Genetic Diversity within Each Population}

To avoid large variation in sample sizes across populations, we used nSSR genotype data from 46 randomly selected adults from TX instead of including data from all 130 individuals from that one population. Within-population genetic diversity parameters i.e. total number of alleles (At), mean number of alleles (An), number of private alleles (Ap), effective number of alleles (Ae), observed (Ho), expected heterozygosity (He), and fixation index (F) based on the three nSSRs were estimated using the program GENALEX 6.5 [38]. Similarly, mean number of alleles (An), number of haplotypes $(\mathrm{Nh})$, and haploid diversity $(\mathrm{H})$ were estimated for the two cpDNA microsatellites using the same program.

\subsubsection{Bottleneck Test and Effective Population Size (Ne)}

Occurrence of bottleneck events in each population was tested using the method described by Cornuet and Luikart [39] by using nSSR data. Three different mutation models, i.e. infinite allele (IAM), stepwise mutation (SMM), and two-phased mutation (TPM) models were used to detect the occurrence of such events. Statistical significance of the test was performed by applying Wilcoxon sign-rank test with 10,000 bootstraps using BOTTLENECK program [39]. Effective population size (Ne) of each population was estimated by using nSSR data based on coalescent-theory and maximum likelihood method employing the program MIGRATE [40]. To estimate Ne, average $\theta$ ( $4 \mathrm{Ne} \mu$, where Ne is the effective population size and $\mu$ is the mutation rate) values for each population were first calculated, and then Ne was estimated assuming an average SSR mutation rate of $10^{-3}$.

\subsubsection{Genetic Diversity among Populations}

Genetic diversity among populations was examined by [41] genetic distance, Wright's [42] $\mathrm{F}_{\mathrm{ST}}$, and an analysis of molecular variance (AMOVA; [43]) based on nuclear and cpDNA SSRs separately by using GENALEX 6.5

Table 1. Primer sequences and genetic diversity estimates of three nuclear microsatellite markers developed for Pogonia ophioglossoides. $\mathrm{T}_{\mathrm{a}}$, range of upper and lower annealing temperatures in touchdown PCR; An, number of alleles; Ho, observed heterozygosity; He, expected heterozygosity.

\begin{tabular}{|c|c|c|c|c|c|c|c|c|}
\hline Locus & Repeat motif & Primer sequence (5'-3') & $\mathrm{T}_{\mathrm{a}}\left({ }^{\circ} \mathrm{C}\right)$ & $\begin{array}{l}\text { Product } \\
\text { size (bp) }\end{array}$ & An & Ho & He & $\begin{array}{l}\text { GenBank } \\
\text { accession }\end{array}$ \\
\hline Po_F7ETL & $(\mathrm{ATGT})_{11}$ & $\begin{array}{l}\text { F: GCATTCCCAAGTCACTTAG } \\
\text { R: CATTCCATGCCTTGTTTG }\end{array}$ & $64-55$ & $137-202$ & 14 & 0.589 & 0.76 & KT984201 \\
\hline Po_GMG1A & $(\mathrm{ATGT})_{7}$ & $\begin{array}{l}\text { F: CCTTCTCGGGAATAAGATAC } \\
\text { R: ATCCTATGCCTACTCACAATC }\end{array}$ & $64-55$ & $142-210$ & 18 & 0.34 & 0.63 & KT984202 \\
\hline Po_FYLXE & $(\mathrm{AT})_{8}(\mathrm{GT})_{7}$ & $\begin{array}{l}\text { F: AAGTGGTCAATAGCCTTTATG } \\
\text { R: AGGGAACATCAAGATTTGTG }\end{array}$ & $61-52$ & $184-250$ & 28 & 0.40 & 0.75 & KT984203 \\
\hline Mean & & & & & 20 & 0.44 & 0.71 & \\
\hline
\end{tabular}

"Product size including M13 tag. 
[44]. An analysis of isolation by distance (IBD) was carried out using the Mantel test by regressing pairwise geographical distance with pairwise $\mathrm{F}_{\mathrm{ST}}$ and Nei's genetic distance for nuclear and cpDNA microsatellites, respectively. The analysis was performed using the program GENALEX 6.5 [44]. Statistical significance test of the regression coefficient was carried out with 9999 bootstraps.

\subsubsection{Inter-Population Genetic Relationships}

Inter-population genetic relationships among the eight populations of $P$. ophioglossoides were examined using cluster analyses. Phylogenetic trees were constructed for both nSSR and cpSSR data using neighbor joining (NJ) method based on [41] genetic distance in the PHYLIP software package [45]. We used 1000 bootstraps and visualized the trees with the program TREEVIEW 1.5 [46]. Principal component analysis (PCA) based on allelic data from three nDNA SSR markers was also performed to evaluate the genetic connection among the populations using the program PCAGEN [47]. Statistical significance test of the PCA was carried out with 10,000 bootstraps. Additionally, genetic structure of the eight sampled populations of $P$. ophioglossoides was estimated based on Bayesian cluster analysis using the STRUCTURE program [48] by using nSSR and cpSSR data. For the analysis, the number of subpopulations $(\mathrm{K})$ was set to 1 to 8 , and 20 runs were carried out for each $\mathrm{K}$ with the burn-in period of 50,000 followed by 100,000 iterations. The optimum number of population clusters was estimated based on $\triangle \mathrm{K}$ parameter according to Evanno et al. [49] using the program STRUCTURE HARVESTER ([50]; http://taylor0.biology.ucla.edu/struct harvest/).

\subsubsection{Fine-Scale Spatial Genetic Structure (FSGS)}

To investigate within-population fine-scale spatial genetic structure (FSGS) in the TX population, allelic nSSR data from all 130 individuals (60 adults and 70 seedlings) were used. Spatial genetic structure for adults and seedlings was estimated separately to compare the FSGS between the two cohorts to estimate the local distribution of genetic variation across the two phenological stages. The analysis was performed based on spatial autocorrelation coefficient (r) method [51] and pair-wise distances in GENALEX 6.2 [44]. This method determines the spatial distribution of genetic variation based on a frequency-weighted average over all alleles from all loci and correlation coefficients of genotypes in relation to their spatial distance.

\section{Results}

\subsection{Genetic Diversity within Populations}

The number of alleles per nSSR locus ranged from 14 to 28 across eight populations of $P$. ophioglossoides (Table 1). Locus-wise observed and expected heterozygosities ranged from 0.395 to 0.579 and 0.627 to 0.760 , respectively. The mean number of alleles over the three nSSR loci and eight populations ranged from six in FL-BCHW to 12 in NJ, with an overall mean of 9.08 (Table 2). A total of 60 alleles at three nSSR loci were observed across eight populations of $P$. ophioglossoides. The overall mean for the effective number of nSSR alleles was 4.79, with the lowest and highest values observed in populations DE $(\mathrm{Ae}=2.92)$ and $\mathrm{NJ}(\mathrm{Ae}=7.21)$, respectively. The value for the observed heterozygosity ( $\mathrm{Ho})$ was the lowest in FL-BCHW ( $\mathrm{Ho}=0.25)$, while it was the highest in $\mathrm{MN}(\mathrm{Ho}=0.57)$. The values of expected heterozygosity $(\mathrm{He})$ ranged from 0.55 in population $\mathrm{DE}$ to 0.81 in GA. The overall mean values for Ho and He were 0.44 and 0.71 , respectively. High values for fixation index ( $F=0.28$ to 0.66 ) were observed in all populations, with an average value of 0.40 . All eight populations showed significant deviation from Hardy-Weinberg expectation. A total of 16 private alleles (Ap) were detected at three nSSRs across eight populations of $P$. ophioglossoides (Table S1, Supplementary Information). Out of the 16 private nSSR alleles, 11 were identified at the nSSR locus FYLXE. Among the eight populations, NJ possessed the highest number of private nSSR alleles $(\mathrm{Ap}=6)$ followed by MN (Ap = 3), DE, FL-JDSP, NC $(\mathrm{Ap}=2)$, and TX $(\mathrm{Ap}=1)$. FL-BCHW was the only population that did not possess any private nSSR alleles.

A total of 11 different cpSSR alleles and 13 unique haplotypes were documented at two cpDNA microsatellites. The highest and lowest number of cpSSR alleles and haplotypes were observed in NJ ( $\mathrm{An}=4.0, \mathrm{Nh}=6.0$ ), and in FL-JDSP and TX (An =1.0, $\mathrm{Nh}=1.0)$, respectively (Table 2). Overall mean values for number of cpSSR alleles and number of haplotypes were 2.06 and 2.88, respectively. A total of five private alleles were detected at the two cpDNA microsatellites (Table S1, Supplementary Information). Of the eight populations, only two populations (NJ and GA) possessed private cpSSR alleles. Similar to the results of nSSRs, the population NJ also contained the highest number of private cpSSR alleles $(\mathrm{Ap}=4)$. 
Table 2. Genetic diversity measures, fixation index, and effective population size of eight Pogonia ophioglossoides populations estimated based on three nuclear and two chloroplast microsatellites. N, number of individuals genotyped; An, mean number of alleles per locus; Ae, effective number of alleles; Ho, observed heterozygosity; He expected heterozygosity; F, fixation index; Ne, effective population size; Nh, number of haplotypes; H, haploid diversity. *indicates deviation from Hardy-Weinberg expectation $(\mathrm{P} \leq 0.05)$.

\begin{tabular}{|c|c|c|c|c|c|c|c|c|c|c|c|}
\hline \multirow{2}{*}{ Population } & \multicolumn{7}{|c|}{ nDNA microsatellites } & \multicolumn{4}{|c|}{ cpDNA microsatellites } \\
\hline & $\mathrm{N}$ & An & Ae & Но & $\mathrm{He}$ & $\mathrm{F}$ & $\mathrm{Ne}$ & $\mathrm{N}$ & An & $\mathrm{Nh}$ & $\mathrm{H}$ \\
\hline GA & 45.00 & 9.67 & 5.71 & 0.48 & 0.81 & $0.41^{*}$ & 329 & 10.00 & 3.00 & 5 & 0.40 \\
\hline FL-BCHW & 36.00 & 6.00 & 3.57 & 0.25 & 0.62 & $0.66^{*}$ & 376 & 10.00 & 1.50 & 2 & 0.09 \\
\hline FL-JDSP & 35.67 & 8.67 & 4.28 & 0.52 & 0.73 & $0.31^{*}$ & 501 & 10.00 & 1.00 & 1 & 0.00 \\
\hline NC & 35.33 & 9.33 & 3.37 & 0.44 & 0.67 & $0.32^{*}$ & 482 & 10.00 & 2.00 & 3 & 0.37 \\
\hline MN & 37.67 & 10.67 & 6.29 & 0.57 & 0.80 & $0.28^{*}$ & 676 & 10.00 & 2.00 & 3 & 0.40 \\
\hline $\mathrm{DE}$ & 35.00 & 7.33 & 2.92 & 0.41 & 0.55 & $0.31^{*}$ & 288 & 10.00 & 2.00 & 2 & 0.18 \\
\hline $\mathrm{TX}$ & 44.67 & 9.00 & 4.93 & 0.45 & 0.77 & $0.41^{*}$ & 297 & 10.00 & 1.00 & 1 & 0.00 \\
\hline NJ & 41.33 & 12.00 & 7.21 & 0.38 & 0.75 & $0.51^{*}$ & 707 & 10.00 & 4.00 & 6 & 0.57 \\
\hline Mean & 38.83 & 9.08 & 4.79 & 0.44 & 0.71 & 0.40 & 457 & 10.00 & 2.06 & 2.88 & 0.25 \\
\hline SE & 0.84 & 0.75 & 0.64 & 0.04 & 0.04 & 0.04 & 12.84 & 0.00 & 0.28 & 1.34 & 0.05 \\
\hline
\end{tabular}

\subsection{Bottleneck Test and Effective Population Size (Ne)}

None of the eight populations showed any significant occurrence of bottleneck events when tested with three different mutation models (data not shown). An overall mean value for the estimated effective population (Ne) size for the eight $P$. ophioglossoides populations was 457 individuals (Table 2). The lowest and highest effective population sizes were estimated for $\mathrm{DE}(\mathrm{Ne}=288)$ and $\mathrm{NJ}(\mathrm{Ne}=707)$, respectively.

\subsection{Genetic Diversity among Populations}

The mean $F_{\text {ST }}$ value for all eight populations was 0.162. The highest genetic differentiation $\left(F_{S T}=0.224\right)$ was detected between DE and FL-BCHW and the lowest genetic differentiation $\left(\mathrm{F}_{\mathrm{ST}}=0.041\right)$ was observed between $\mathrm{NJ}$ and TX. Also, DE had the highest $\mathrm{F}_{\mathrm{ST}}$ values against the remaining populations, including the most proximal NJ. However, all pairs of populations showed significant genetic differentiation (Table S2, Supplementary Information). Genetic differentiation estimated based on hierarchical AMOVA showed that $21 \%\left(\Phi_{\mathrm{PT}}=0.21, \mathrm{P}=\right.$ $0.000)$ and $63 \%\left(\Phi_{\mathrm{PT}}=0.63, \mathrm{P}=0.000\right)$ genetic diversity was distributed among populations estimated based on nuclear and cpDNA microsatellites, respectively (Table S3, Supplementary Information). The isolation by distance estimate based on Mantel test did not show an association between genetic differentiation and geographic distance based on nSSRs (Mantel test, $\mathrm{r}^{2}=0.031, \mathrm{P}=0.235$ ). However, IBD was significant based on cpSSRs $\left(r^{2}=0.213, P=0.005\right)$ (Figure S2, Supplementary Information).

\subsection{Inter-Population Genetic Relationship}

The neighbor joining dendrogram constructed based on nSSRs did not show any grouping of individuals according to geographic proximity (Figure 2). However, a similar tree constructed based on cpDNA microsatellites showed three distinct groupings. Among the six east coast populations, the two populations from Florida (FL-BCHW and FL-JDSP) formed one group, and the remaining four (DE, GA, NC and NJ) grouped together. The two central US populations (TX and MN) formed a separate group. Somewhat similar to the cPSSR neighbor joining tree, the PCA based on nSSR data clustered the two populations from Florida (FL-BCHW and FLJDSP) and NC together in one group, and the two central US populations (TX and MN) in a separate group (Figure S3, Supplementary Information). Remaining populations (DE, GA and NJ) did not form any clustering although DE was distinctly segregated from other populations. The percentage of inertia for the first and second coordinates of the nSSR based PCA were 39\% $(P=0.075)$ and $24 \%(P=0.116)$, respectively. 
STRUCTURE analysis based on nSSRs divided the eight populations of $P$. ophioglossoides into two groups (K = 2; Group 1 - FL-BCHW, FL-JDSP, GA and NC, Group 2 - DE, MN, NJ and TX; Figure 1(a) and Figure S4(a), Supplementary Information). However, the same analysis based on two cpSSRs grouped the eight populations into three groups (K = 3; Group 1-FL-BCHW, FL-JDSP, GA, MN, and TX, Group 2-NC and NJ, Group 3-DE; Figure 1(b) and Figure S4(b), Supplementary Information).

\subsection{Fine-Scale Spatial Genetic Structure (FSGS)}

The FSGS analysis based on spatial autocorrelation coefficient (r) showed positive FSGS up to $40 \mathrm{~m}$ for adult plants and up to $30 \mathrm{~m}$ for seedlings in this population (Figure 3). A negative FSGS was observed from the

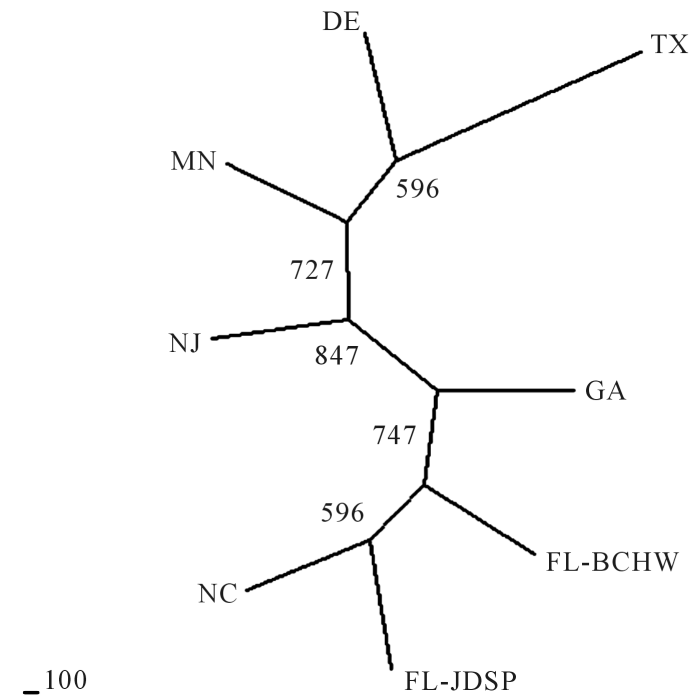

(a)

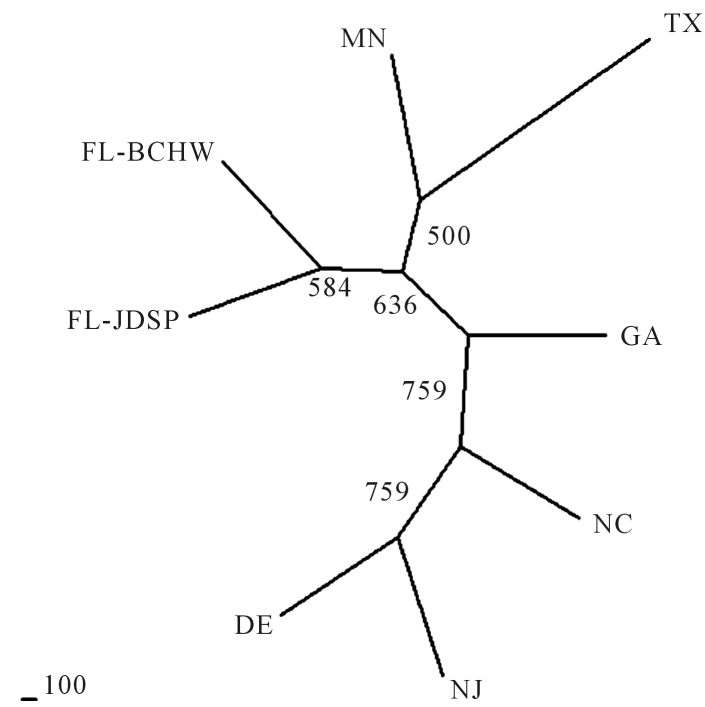

(b)

Figure 2. Unrooted neighbor joining trees of eight Pogonia ophioglossoides populations constructed using Nei's [41] genetic distances based on three nuclear microsatellites (a) and two chloroplast microsatellites (b). Values by the nodes are the number of bootstrap supporting the grouping out of 1000 bootstraps and only the values $\geq 500$ are displayed.

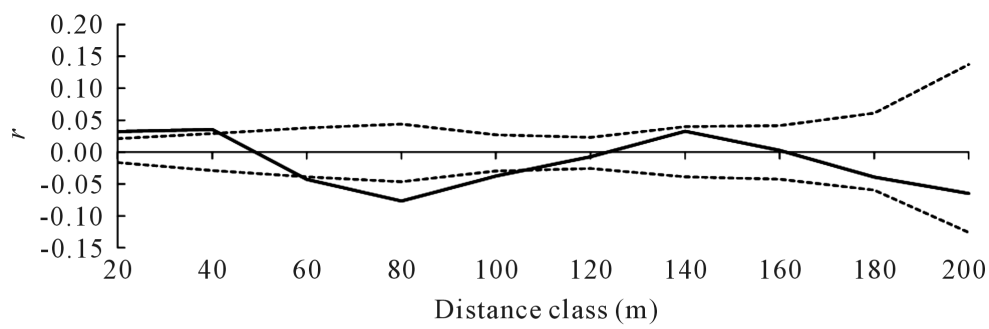

(a)

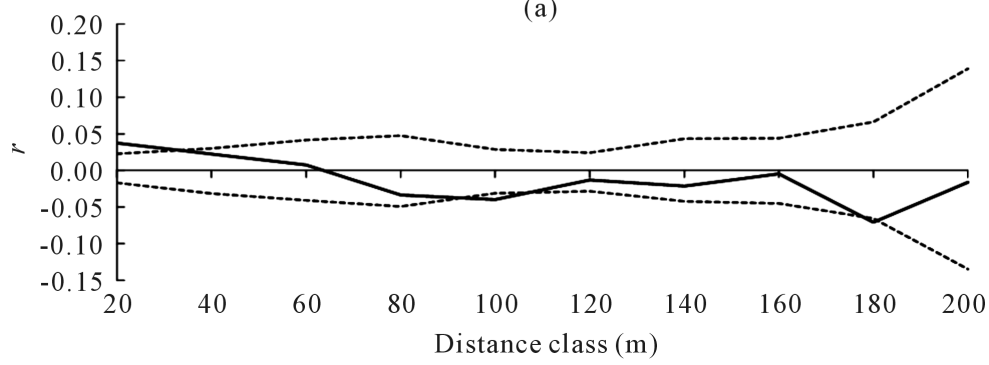

(b)

Figure 3. Autocorrelation coefficient (r, solid line) estimated for adult plants (a) and seedlings (b) of Pogonia ophioglossoides, and plotted against geographic distance intervals. Dashed lines represent upper and lower 95\% confidence limits obtained after 9999 bootstraps. 
distance $60 \mathrm{~m}$ to $110 \mathrm{~m}$ for adults, and from $90 \mathrm{~m}$ to $110 \mathrm{~m}$ for seedlings. These results show that the Texas population contains clusters of individuals with similar genetic information.

\section{Discussion}

\subsection{Species Specific Microsatellites}

Three self-developed, polymorphic nuclear microsatellites showed high variation in Pogonia ophioglossoides (Table 1). Although this number of SSRs is less than the number typically used in other species, it is compensated to some extent by the highly polymorphic nature of these three markers. For example, the total number of alleles per species ranged from 31 to 58 in six studies on orchid taxa that employed between six and nine SSRs each [30] [52]-[56]. In comparison, we detected 60 total alleles across three nSSRs in $P$. ophioglossoides, whereby the polymorphism per locus is considerably higher than the values reported above. Although a greater number of loci can provide better resolution, these three microsatellites can certainly assist in assessing population and conservation genetics of $P$. ophioglossoides and possibly other Pogonia species by allowing an assessment of genetic diversity within and between populations, micro-scale spatial genetic structure, mating system and gene flow, and identical multilocus genotypes, etc. until additional markers become available.

\subsection{Genetic Diversity and Population Structure}

We report as much or higher genetic diversity in Pogonia ophioglossoides as compared to other common terrestrial orchids that used nSSR markers (e.g. Anacamptis palustris, [57]; Ophrys species, [58]; Gymnadenia conopsea, [59]; Caladenia huegelii, [24]; Platanthera praeclara, [60]). The relatively high level of genetic variation observed in P. ophioglossoides can be explained by the outcrossing characteristic and presence of populations ranging from 100 to several hundred individuals per population (from field observation) across a wide distribution range. This was also further confirmed by the estimates of effective population sizes (Ne) that ranged from 297 to 707 with the mean value of 457. Despite the high genetic diversity at nSSR loci, the genetic diversity estimate based on cpDNA microsatellites was similar or lower than it was reported in other orchids (e.g., Anacamptis palustris, [57]; Cypripedium calceolus, [31]; Chiloglottis species, [61]). The lower level of cpDNA microsatellite diversity in $P$. ophioglossoides is likely due to restriction in gene flow through seed dispersal among populations because the chloroplast genome is maternally inherited in flowering plants and movement of chloroplast genetic variation in nature can occur only through seed dispersal.

All eight populations included in our study showed high (mean $\mathrm{F}=0.40$ ) and significant deviation from Hardy-Weinberg expectation. The high inbreeding estimate could be a result of mating among close relatives, or due to selfing. Pogonia ophioglossoides produces flowers that are odorous, may offer small amounts of nectar as a reward to pollinators, and contain granular pollinia. Insect-assisted outcrossing is reported to be the primary pollination syndrome, however, when hand pollination was employed, plants yielded up to 95\% fruit set [26] [27]. Selfing, though, is unlikely in nature [27], and thus the high F detected in the study populations is likely a result of mating among close relatives. Our FSGS data also corroborate the presence of this phenomenon because we observed spatial autocorrelation among adults and seedlings up to $40 \mathrm{~m}$ within a large population. Thus, mating and seed dispersal can be inferred to be localized within individual populations.

Another explanation for the strongly positive fixation index could be due to presence of a subpopulation structure known as Wahlund effect that can create two or more subpopulations with different allelic frequencies to reduce the observed heterozygosity among subpopulations facing geographic barriers. While employing AFLPs, Chung and Chung [19] reported high level of fixation $(\mathrm{F}=0.257)$ in a closely related but endangered Pogonia minor across its three small and isolated populations; the result were attributed to selfing and Wahlund effects. Additionally, [62] reported a very high fixation index in Isotria medeoloides ( $F=0.95)$ which is an orchid within the tribe Pogonieae and the result was explained by its predominantly selfing characteristics. Similarly, high fixation was also reported in a critically endangered Australian orchid Caladenia huegelii with highly fragmented populations and low fruit-set owing to its reliance on sexual deception for pollination (mean $F=$ 0.22; [24]) and in a self-compatible and mixed-mating east-Asian orchid Cephalanthera longibracteata (mean $F=0.33$; [15]) and the results were attributed to Wahlund effects and/or inbreeding effects.

The mean population differentiation in $P$. ophioglossoides measured by $\mathrm{F}_{\mathrm{ST}}$ was higher $\left(\mathrm{F}_{\mathrm{ST}}=0.162\right)$ than the mean $\mathrm{F}_{\mathrm{ST}}$ estimated for orchids $\left(\mathrm{F}_{\mathrm{ST}}=0.146\right.$; reviewed in Phillips et al. [63]). However, the mean $\mathrm{F}_{\mathrm{ST}}$ value in 
Phillips et al. [63] was estimated mostly from the studies that used low-resolution polymorphic markers such as allozymes. Considering that the microsatellite markers used in the current study are highly polymorphic, the mean $\mathrm{F}_{\mathrm{ST}}$ value 0.162 can be considered high. Moreover, AMOVA revealed that $21 \%$ of total genetic variation $\left(\Phi_{\mathrm{PT}}=0.21, \mathrm{P}=0.000\right)$ was distributed among populations. The observed high differentiation among populations is likely due to restricted gene flow between the disjunct populations sampled in this study. Additionally, the AMOVA estimated based on cpDNA microsatellites showed that $63 \%\left(\Phi_{\mathrm{PT}}=0.63, \mathrm{P}=0.000\right)$ of total genetic variation was among populations. This result suggests that there is a barrier in gene flow through seed dispersal specifically because of the exclusive maternal inheritance of chloroplast DNA. Many studies in orchids have reported a lower level of population differentiation than reported in the present study (e.g. [16] [24] [58] [64]. Most of them identified high gene flow between populations through pollen, and/or seed dispersal as the potential causes. Conversely, higher population differentiation (mean $\mathrm{R}_{\mathrm{ST}}=0.485$; [62]) than in our study was reported for another member of the Pogonieae, Isotria medeoloides, which though is a much rarer species with high occurrence of autogamy [27] [65].

Most of the cluster analyses including Neighbor-joining trees and STRUCTURE based on both nDNA and cpDNA microsatellites showed that the two populations from Florida (FL-BCW and FL-JDSP) and one from Georgia (GA) grouped together. This result suggests that the three populations may have originated from the same gene pool. No significant inter-population isolation by distance (IBD) was detected with the Mantel test in P. ophioglossoides based on both nuclear and cpSSRs, which indicates that genetic differentiation between populations is not directly correlated with the spatial distance between them, and that despite the wide natural range of this species, relatively large populations, and the outcrossing pollination mechanism, genetic drift, inbreeding, or selection are occurring independently in each population.

\subsection{Fine-Scale Spatial Genetic Structure (FSGS)}

The positive spatial autocorrelation up to $40 \mathrm{~m}$ in the TX population of $P$. ophioglossoides suggests non-random distribution of genetic variation or clustering of individuals with similar genetic information within this population. Considering that this is a relatively large population, it can infer that the smaller populations would show similar patterns, and that localized family structure is created by short distance dispersal of pollen and/or seeds. The spatial distribution of $P$. ophioglossoides plants in the TX population (Figure S1, Supplementary Information) whereby the individuals are clustered mainly in three groups also suggests localized seed dispersal in this species, although this pattern could also be related to the distribution of other biotic (e.g., mycorrhizal) or abiotic characteristics that affect recruitment of new individuals. However, the genetic relatedness of the plants in each cluster suggests that dispersal is likely more responsible for the distribution of individuals.

While microscopic, dust-like orchid seeds generally are assumed and expected to disperse over long distances through wind and water, a modelling-based study by Murren and Ellison [66] reported that wind-mediated mean seed dispersal distance was less than $6 \mathrm{~m}$ in an epiphytic orchid Brassavola nodosa. Similarly, Jacquemyn et al. [67] reported median seed dispersal distance of up to $7 \mathrm{~m}$ in a terrestrial orchid Orchis purpurea based on parentage analysis. Although both pollen and seed dispersal play a role in the movement of genetic information in plants, empirical studies have shown that fine-scale SGS is influenced more by seed than pollen dispersal [68] [69]. A very short distance (up to $2 \mathrm{~m}$ ) SGS was reported in a closely related orchid P. minor [19] and a shortdistance SGS was reported in other terrestrial orchids such as Caladenia tentaculata [38], Cymbidium goeringii [14], and Cephalanthera longibracteata [15]. Consistent with our explanation, these studies also deduced the localized seed dispersal to be the primary reason for the occurrence of FSGS in their respective studies.

\subsection{Conservation Implications}

Biodiversity conservation utilizes the knowledge of genetic resources and their distribution in the species of interest [5] [70]. The Orchidaceae, which is one of the most diverse angiosperm families also contains the highest number of species that are considered rare or infrequent. Knowledge of genetic diversity structures of taxa with specialized life histories then becomes important to explain their evolutionary trajectories in the context of biological and anthropogenic pressures. Our results indicate that a widely distributed and locally common orchid, Pogonia ophioglossoides, holds high genetic diversity within its disjunct populations. All populations are significantly diverged from each other without exhibiting evidence for isolation by distance. The population in New Jersey stands out with its high allelic diversity, high number of private alleles, and relatively high diver- 
gence from the remaining populations, including the most geographically proximal population in Delaware. Allelic data from chloroplast SSRs, which are maternally inherited and evolve slowly, indicated high divergence (63\%) across populations indicating that seed dispersal is restricted. The FSGS results support this observation and amplify the need for using genetic information to guide the conservation efforts that utilize assisted pollination, artificial propagation, and/or population augmentation.

\section{Acknowledgements}

We gratefully acknowledge the assistance of the listed individuals in obtaining permits and collecting lea tissues for the study: William McAvoy (Delaware), Stephen Dickman (Florida), Matt Richards (Florida and Georgia), Erika Rowe (Minnesota), David McAdoo (North Carolina), Phil Oyerly and David Snyder (New Jersey), Tom Phillips, Joe Liggio, and Peter Loos (Texas).

\section{References}

[1] Dressler, R.L. (1993) Phylogeny and Classification of the Orchid Family. Dioscorides Press, Portland.

[2] Cozzolino, S., Cafasso, D., Pellegrino, G., Musacchio, A. and Widmer, A. (2003) Molecular Evolution of a Plastid Tandem Repeat Locus in an Orchid Lineage. Journal of Molecular Evolution, 57, S41-S49. http://dx.doi.org/10.1007/s00239-003-0006-3

[3] Tremblay, R.L., Ackerman, J.D., Zimmerman, J.K. and Calvo, R.N. (2005) Variation in Sexual Reproduction in Orchids and Its Evolutionary Consequences: A Spasmodic Journey to Diversification. Biological Journal of the Linnean Society, 84, 1-54. http://dx.doi.org/10.1111/j.1095-8312.2004.00400.x

[4] Heschel, M.S. and Paige, K.N. (1995) Inbreeding Depression, Environmental Stress, and Population Size Variation in Scarlet Gilia (Ipomopsisaggregata). Conservation Biology, 9, 126-133. http://dx.doi.org/10.1046/j.1523-1739.1995.09010126.x

[5] Frankham, R., Ballou, J.D. and Briscoe, D.A. (2002) Introduction to Conservation Genetics. Cambridge University Press, Cambridge. http://dx.doi.org/10.1017/CBO9780511808999

[6] Aguilar, R., Quesada, M., Ashworth, L., Herrerias-Diego, Y. and Lobo, J. (2008) Genetic Consequences of Habitat Fragmentation in Plant Populations: Susceptible Signals in Plant Traits and Methodological Approaches. Molecular Ecology, 17, 5177-5188. http://dx.doi.org/10.1111/j.1365-294X.2008.03971.x

[7] Cole, C.T. (2003) Genetic Variation in Rare and Common Plants. Annual Review of Ecological Systematics, 34, 213237. http://dx.doi.org/10.1146/annurev.ecolsys.34.030102.151717

[8] Gitzendanner, M.A. and Soltis, P.S. (2000) Patterns of Genetic Variation in Rare and Widespread Plant Congeners. American Journal of Botany, 87, 783-792. http://dx.doi.org/10.2307/2656886

[9] Honnay, O. and Jacquemyn, H. (2007) Susceptibility of Common and Rare Plant Species to the Genetic Consequences of Habitat Fragmentation. Biological Conservation, 21, 823-831. http://dx.doi.org/10.1111/j.1523-1739.2006.00646.x

[10] Sokal, R.R. and Oden, N.L. (1978) Spatial Autocorrelation in Biology 1. Methodology. Biological Journal of Linnean Society, 10, 199-228. http://dx.doi.org/10.1111/j.1095-8312.1978.tb00013.x

[11] Slatkin, M. and Arter, H.E. (1991) Spatial Autocorrelation Methods in Population Genetics. The American Naturalist, 138, 499-517. http://dx.doi.org/10.1086/285228

[12] Young, A., Boyle, T. and Brown, T. (1996) The Population Genetic Consequences of Habitat Fragmentation for Plants. Trends in Ecology and Evolution, 11, 413-418. http://dx.doi.org/10.1016/0169-5347(96)10045-8

[13] Vekemans, X. and Hardy, O.J. (2004) New Insights from Fine-Scale Spatial Genetic Structure Analyses in Plant Populations. Molecular Ecology, 13, 921-934. http://dx.doi.org/10.1046/j.1365-294X.2004.02076.x

[14] Chung, M.Y., Chung, G.M., Chung, M.G. and Epperson, B. (1998) Spatial Genetic Structure in Populations of Cymbidium goeringii (Orchidaceae). Genes Genetics Systematics, 73, 281-285. http://dx.doi.org/10.1266/ggs.73.281

[15] Chung, M.Y., Nason, J.D. and Chung, M.G. (2004) Spatial Genetic Structure in Populations of the Terrestrial Orchid Cephalantheralongibracteata (Orchidaceae). American Journal of Botany, 91, 52-57. http://dx.doi.org/10.3732/ajb.91.1.52

[16] Chung, M.Y., Nason, J.D. and Chung, M.G. (2005) Spatial Genetic Structure in Populations of the Terrestrial Orchid Orchis cyclochila (Orchidaceae). Plant Systematics and Evolution, 254, 209-219. http://dx.doi.org/10.1007/s00606-005-0341-5

[17] Jacquemyn, H., Brys, R., Vandepitte, K., Honnay, O. and Roldan-Ruiz, I. (2006) Fine-Scale Genetic Structure of Life History Stages in the Food-Deceptive Orchid Orchis purpurea. Molecular Ecology, 15, 2801-2808. 
http://dx.doi.org/10.1111/j.1365-294X.2006.02978.x

[18] Matsui, K., Ushimaru, A. and Fujita, N. (2001) Pollinator Limitation in a Deceptive Orchid, Pogonia japonica, on a Floating Peat Mat. Plant Species Biology, 16, 231-235. http://dx.doi.org/10.1046/j.1442-1984.2001.00067.x

[19] Chung, M.Y. and Chung, M.G. (2008) Conservation Genetics of the Endangered Terrestrial Orchid Pogonia minor in South Korea. Annales Botanici Fennici, 45, 455-464. http://dx.doi.org/10.5735/085.045.0604

[20] Case, M.A., Mlodozeniec, H.T., Wallace, L.E. and Weldy, T.W. (1998) Conservation Genetics and Taxonomic Status of the Rare Kentucky Lady's Slipper: Cypripedium kentuckiense (Orchidaceae). American Journal of Botany, 85, 17791786. http://dx.doi.org/10.2307/2446512

[21] Forrest, A.D., Hollingsworth, M.L., Hollingsworth, P.M., Sydes, C. and Bateman, R.M. (2004) Population Genetic Structure in European Populations of Spiranthes romanzoffiana Set in the Context of Other Genetic Studies on Orchids. Heredity, 92, 218-227. http://dx.doi.org/10.1038/sj.hdy.6800399

[22] Chung, J.M., Park, K.W., Park, C.-S., Lee, S.-H., Chung, M.G. and Chung, M.Y. (2009) Contrasting Levels of Genetic Diversity between the Historically Rare Orchid Cypripedium japonicum and the Historically Common Cypripedium macranthos in South Korea. Botanical Journal of Linnean Society, 160, 119-129. http://dx.doi.org/10.1111/j.1095-8339.2009.00965.X

[23] George, S., Sharma, J. and Yadon, V.L. (2009) Genetic Diversity of the Endangered and Narrow Endemic Piperia yadonii (Orchidaceae) Assessed with ISSR Polymorphisms. American Journal of Botany, 96, 2022-2030. http://dx.doi.org/10.3732/ajb.0800368

[24] Swarts, N.D., Sinclair, E.A., Krauss, S.L. and Dixon, K.W. (2009) Genetic Diversity in Fragmented Populations of the Critically Endangered Spider Orchid Caladenia huegelii: Implications for Conservation. Conservation Genetics, 10, 1199-1208. http://dx.doi.org/10.1007/s10592-008-9651-9

[25] Light, M.L. and Sharma, J. (2010) Comparison of in Situ Germination of Pogonia ophioglossoides in the Northern and Southern Parts of Its Range. Native Orchid Conference Journal, 7, 12-24.

[26] Thien, L.B. and Marcks, B.G. (1972) The Floral Biology of Arethusa bulbosa, Calopogon tuberosus, and Pogonia ophioglossoides (Orchidaceae). Canadian Journal of Botany, 50, 2319-2325. http://dx.doi.org/10.1139/b72-300

[27] Argue, C.L. (2012) Tribe Arethuseae (Calopogon R. Brown and Arethusa L.) and Subfamily Vanilloideae (Part One) (Pogonia Jussieu). Chapter 8. In: Argue, C.L., Ed., The Pollination Biology of North American Orchids: Volume 2, Springer, New York, 147-164. http://dx.doi.org/10.1007/978-1-4614-0622-8_8

[28] NatureServe (2015) NatureServe Explorer: An Online Encyclopaedia of Life (Web Application). Version 7.1, NatureServe, Arlington, Virginia. http://www.natureserve.org/explorer

[29] Pandey, M. and Sharma, J. (2012) Efficiency of Microsatellite Isolation from Orchids via Next Generation Sequencing. Open Journal of Genetics, 2, 167-172. http://dx.doi.org/10.4236/ojgen.2012.24022

[30] Pandey, M. and Sharma, J. (2013) Characterization of Microsatellite Loci for Cypripedium kentuckiense (Orchidaceae). Conservation Genetics, 5, 1031-1033. http://dx.doi.org/10.1007/s12686-013-9961-1

[31] Fay, M.F., Bone, R., Cook, P., et al. (2009) Genetic Diversity in Cypripedium calceolus (Orchidaceae) with a Focus on North-Western Europe, as Revealed by Plastid DNA Length Polymorphisms. Annals of Botany, 104, 517-525. http://dx.doi.org/10.1093/aob/mcp116

[32] Micheneau, C., Duffy, K.J., Smith, R.J., Stevens, L.J., Stout, J.C., Civeyrel, L., Cowan, R.S. and Fay, M.F. (2010) Plastid Microsatellites for the Study of Genetic Variability in the Widespread Cephalanthera longifolia, C. damasonium and C. rubra (Neottieae, Orchidaceae), and Cross Amplification in Other Cephalanthera Species. Botanical Journal of Linnean Society, 163, 181-193. http://dx.doi.org/10.1111/j.1095-8339.2010.01053.x

[33] Taberlet, P., Gielly, L., Pautou, G. and Bouvet, J. (1991) Universal Primers for Amplification of Three Non-Coding Regions of Chloroplast DNA. Plant Molecular Biology, 17, 1105-1109. http://dx.doi.org/10.1007/BF00037152

[34] Small, R.L., Ryburn, J.A., Cronn, R.C., Seelanan, T. and Wendel, J.F. (1998) The Tortoise and the Hare: Choosing between Noncoding Plastome and Nuclear Adh Sequences for Phylogeny Reconstruction in a Recently Diverged Plant Group. American Journal of Botany, 85, 1301-1315. http://dx.doi.org/10.2307/2446640

[35] Oxelman, B., Liden, M. and Berglund, D. (1997) Chloroplast rps16 Intron Phylogeny of the Tribe Sileneae (Caryophyllaceae). Plant Systematics and Evolution, 206, 393-410. http://dx.doi.org/10.1007/BF00987959

[36] Micheneau, C. (2002) Relations phylogénétiques des Neottieae (Orchidaceae) etétude de la variabilitégénétique de Cephalanthera longifolia à l'aide de marqueursmoléculaires (séquençage et microsatellites chloroplastiques). DEA mémoire, Muséum National d'Histoire Naturelle, Paris.

[37] Shaw, J., Lickey, E.B., Schilling, E.E. and Small, R.L. (2007) Comparisons of Whole Chloroplast Genome Sequences to Choose Noncoding Regions for Phylogenetic Studies in Angiosperms: The Tortoise and the Hare III. American Journal of Botany, 94, 275-288. http://dx.doi.org/10.3732/ajb.94.3.275 
[38] Peakall, R. and Beattie, A.J. (1996) Ecological and Genetic Consequences of Pollination by Sexual Deception in the Orchid Caladenia tentaculata. Evolution, 50, 2207-2220. http://dx.doi.org/10.2307/2410692

[39] Cornuet, J. and Luikart, G. (1996) Description and Power Analysis of Two Tests for Detecting Recent Population Bottlenecks from Allele Frequency Data. Genetics, 144, 2001-2005.

[40] Beerli, P. and Felsenstein, J. (1999) Maximum Likelihood Estimation of Migration Rates and Population Numbers of Two Populations Using a Coalescent Approach. Genetics, 152, 763-773.

[41] Nei, M. (1972) Genetic Distance between Populations. The American Naturalist, 106, 283-292. http://dx.doi.org/10.1086/282771

[42] Wright, S. (1965) The Interpretation of Population Structure by F-Statistics with Special Regard to Systems of Mating. Evolution, 19, 395-420. http://dx.doi.org/10.2307/2406450

[43] Excoffier, L., Smouse, P.E. and Quattro, J.M. (1992) Analysis of Molecular Variance Inferred from Metric Distances among DNA Haplotypes: Application to Human Mitochondrial DNA Restriction Sites. Genetics, 131, 479-491.

[44] Peakall, R. and Smouse, P.E. (2006) GENALEX 6: Genetic Analysis in Excel. Population Genetic Software for Teaching and Research. Molecular Ecology Notes, 6, 288-295. http://dx.doi.org/10.1111/j.1471-8286.2005.01155.x

[45] Felsenstein, J. (1995) Phylip (Phylogeny Inference Package). Department of Genetics, University of Washington, Seattle.

[46] Page, R.D.M. (1996) TREEVIEW: An Application to Display Phylogenetic Trees on Personal Computers. Computer Application in Bioscience, 12, 357-358.

[47] Goudet, J. (1999) PCAGEN. Principal Component Analysis of Gene Frequency Data (Version 1.2). http://www2.unil.ch/popgen/softwares/pcagen.htm

[48] Pritchard, J.K., Stephens, M. and Donnelly, P. (2000) Inference of Population Structure Using Multilocus Genotype Data. Genetics, 155, 945-959.

[49] Evanno, G., Regnaut, S. and Goudet, J. (2005) Detecting the Number of Clusters of Individuals Using the Software Structure: A Simulation Study. Molecular Ecology, 14, 2611-2620. http://dx.doi.org/10.1111/j.1365-294x.2005.02553.x

[50] Earl, D.A. and von Holdt, B.M. (2012) STRUCTURE HARVESTER: A Website and Program for Visualizing STRUCTURE Output and Implementing the Evanno Method. Conservation Genetics Resources, 4, 359-361. http://dx.doi.org/10.1007/s12686-011-9548-7

[51] Smouse, P.E. and Peakall, R. (1999) Spatial Autocorrelation Analysis of Individual Multiallele and Multilocus Genetic Structure. Heredity, 82, 561-573. http://dx.doi.org/10.1038/sj.hdy.6885180

[52] Gustafson, S. and Thorén, P.A. (2001) Microsatellite Loci in Gymnadenia conopsea, the Fragrant Orchid. Molecular Ecology Notes, 1, 81-82. http://dx.doi.org/10.1046/j.1471-8278.2001.00033.X

[53] Boonsrangsom, T., Pongtongkam, P., Masuthon, S. and Peyachoknagul, S. (2008) Development of Microsatellite Markers for Dendrobium Orchids. Thai Journal of Genetics, 1, 47-56.

[54] Pinheiro, F., Santos, M.O., Barros, F., et al. (2008) Isolation and Characterization of Microsatellite Loci in the Brazilian Orchid Epidendrum fulgens. Conservation Genetics, 9, 1661-1663. http://dx.doi.org/10.1007/s10592-008-9514-4

[55] Phuekvilai, P., Pradit, P. and Surin, P. (2009) Development of Microsatellite Markers for Vanda Orchid. Kasetsart Journal of Natural Science, 43, 497-506.

[56] Hopkins, S.E. and Taylor, D.L. (2011) Microsatellite Loci Development in Mycoheterotrophic Corallorhiza maculata (Orchidaceae) with Amplification in C. mertensiana. American Journal of Botany, 98, e253-e255. http://dx.doi.org/10.3732/ajb.1100061

[57] Cozzolino, S., Cafasso, D., Pellegrino, G., Musacchio, A. and Widmer, A. (2003) Fine-Scale Phylogeographical Analysis of Mediterranean Anacamptis palustris (Orchidaceae) Populations Based on Chloroplast Minisatellite and Microsatellite Variation. Molecular Ecology, 12, 2783-2792. http://dx.doi.org/10.1046/j.1365-294X.2003.01958.x

[58] Soliva, M. and Widmer, A. (2003) Gene Flow across Species Boundaries in Sympatric, Sexually Deceptive Ophrys (Orchidaceae) Species. Evolution, 57, 2252-2261. http://dx.doi.org/10.1111/j.0014-3820.2003.tb00237.x

[59] Campbell, V.V., Rowe, G., Beebee, T.J.C. and Hutchings, M.J. (2007) Genetic Differentiation amongst Fragrant Orchids (Gymnadenia conopseas L.) in the British Isles. Botanical Journal of Linnaeus Society, 155, 349-360. http://dx.doi.org/10.1111/j.1095-8339.2007.00709.x

[60] Ross, A.A., Aldrich-Wolfe, A., Lance, S., Glenn, T. and Travers, S.E. (2013) Microsatellite Markers in the Western Prairie Fringed Orchid, Platanthera praeclara (Orchidaceae). Application in Plant Sciences, 1, Article ID: 1200413. http://dx.doi.org/10.3732/apps.1200413

[61] Ebert, D., Hayes, C. and Peakall, R. (2009) Chloroplast Simple Sequence Repeat Markers for Evolutionary Studies in 
the Sexually Deceptive Orchid Genus Chiloglottis. Molecular Ecology Resources, 9, 673-690. http://dx.doi.org/10.1111/j.1755-0998.2008.02319.x

[62] Stone, J.L., Crystal, P.A., Devlin, E.E., Le, B., Downer, R.H. and Cameron, D.S. (2012) Highest Genetic Diversity at the Northern Range Limit of the Rare Orchid Isotria medeoloides. Heredity, 109, 215-221. http://dx.doi.org/10.1038/hdy.2012.31

[63] Phillips, R., Dixon, K. and Peakall, R. (2012) Low Population Genetic Differentiation in the Orchidaceae: Implications for the Diversification of the Family. Molecular Ecology, 21, 5208-5220. http://dx.doi.org/10.1111/mec.12036

[64] Duffy, K.J., Scopece, G., Cozzolino, S., Fay, M.F., Smith, R.J. and Stout, J.C. (2009) Ecology and Genetic Diversity of the Dense-Flowered Orchid, Neotinea maculata, at the Centre and Edge of Its Range. Annals of Botany, 104, 507-516. http://dx.doi.org/10.1093/aob/mcn200

[65] Vitt, P. and Campbell, C.S. (1997) Reproductive Biology of Isotria medeoloides (Orchidaceae). Rhodora, 99, 56-63.

[66] Murren, C.J. and Ellison, A.M. (1998) Seed Dispersal Characteristics of Brassavola nodosa (Orchidaceae). American Journal of Botany, 85, 675-680. http://dx.doi.org/10.2307/2446537

[67] Jacquemyn, H., Brys, R., Vandepitte, K., Honnay, O., Roldán-Ruiz, I. and Wiegand, T. (2007) A Spatially-Explicit Analysis of Seedling Recruitment in the Terrestrial Orchid Orchis purpurea. New Phytologist, 176, 448-459. http://dx.doi.org/10.1111/j.1469-8137.2007.02179.x

[68] Hamrick, J.L. and Nason, J.D. (1996) Consequences of Dispersal in Plants. In: Rhodes Jr., O.E., Chesser, R.K. and Smith, M.H., Eds., Population Dynamics in Ecological Space and Time, University of Chicago Press, Chicago, 203236.

[69] Kalisz, S., Nason, J.D., Hanzawa, F.A. and Tonsor, S.J. (2001) Spatial Genetic Structure in Trillium grandiflorum: The Roles of Dispersal, Mating, History and Selection. Evolution, 55, 1560-1568. http://dx.doi.org/10.1111/j.0014-3820.2001.tb00675.x

[70] Lande, R. (1988) Genetics and Demography in Biological Conservation. Science, 241, 1455-1460. http://dx.doi.org/10.1126/science.3420403 


\section{Supplementary Information}

Table S1. Private alleles of microsatellites and their frequency detected in eight populations of Pogonia ophioglossoides.

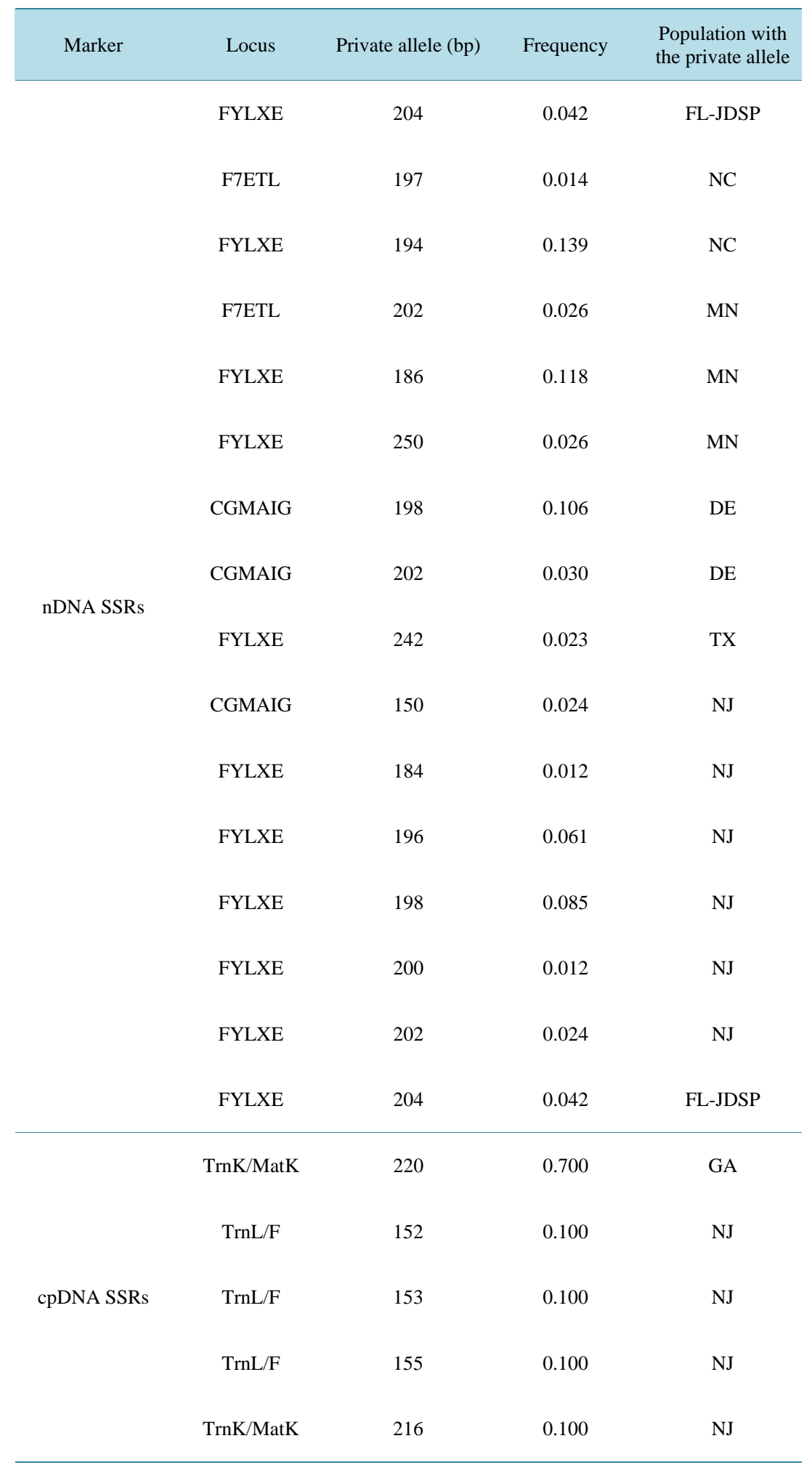


Table S2. Pair-wise geographic distances (km) above diagonal and pair-wise Wright's [42] FST below diagonal for eight populations of Pogonia ophioglossoides based on three nuclear microsatellites. ${ }^{*}$ indicates FST values with P $\leq 0.05$.

\begin{tabular}{ccccccccc}
\hline Population & GA & FL-BCHW & FL-JDSP & NC & MN & DE & TX & NJ \\
\hline GA & - & 449 & 600 & 422 & 2010 & 963 & 1156 & 1074 \\
FL-BCHW & $0.059^{*}$ & - & 269 & 780 & 2391 & 1366 & 1166 & 1481 \\
FL-JDSP & $0.048^{*}$ & $0.061^{*}$ & - & 804 & 2603 & 1388 & 1432 & 1503 \\
NC & $0.054^{*}$ & $0.066^{*}$ & $0.044^{*}$ & - & 2040 & 590 & 1544 & 706 \\
MN & $0.065^{*}$ & $0.136^{*}$ & $0.098^{*}$ & $0.096^{*}$ & - & 1850 & 1830 & 1828 \\
DE & $0.160^{*}$ & $0.224^{*}$ & $0.192^{*}$ & $0.206^{*}$ & $0.157^{*}$ & - & 1933 & 116 \\
TX & $0.052^{*}$ & $0.117^{*}$ & $0.096^{*}$ & $0.107^{*}$ & $0.052^{*}$ & $0.143^{*}$ & - & 2017 \\
NJ & $0.049^{*}$ & $0.105^{*}$ & $0.090^{*}$ & $0.090^{*}$ & $0.076^{*}$ & $0.172^{*}$ & $0.041^{*}$ \\
\hline
\end{tabular}

Table S3. Results of AMOVA based on eight nuclear and two chloroplast microsatellites across eight populations of Pogonia ophioglossoides. df, degrees of freedom; SS, sum of squares; P, P-value, or the estimated probability of rejecting the null hypothesis.

\begin{tabular}{|c|c|c|c|c|c|c|}
\hline Marker type & Source & $\mathrm{df}$ & SS & Estimated variation & $\%$ variation & $\mathrm{P}$ \\
\hline \multirow{2}{*}{ nDNA microsatell } & Among population & 7 & 247 & 0.815 & 21 & 0.00 \\
\hline & Within population & 308 & 969 & 3.147 & 79 & \\
\hline \multirow{2}{*}{ cpDNA microsatel } & Among population & 7 & 198 & 2.668 & 63 & 0.00 \\
\hline & Within population & 72 & 113 & 1.575 & 37 & \\
\hline
\end{tabular}

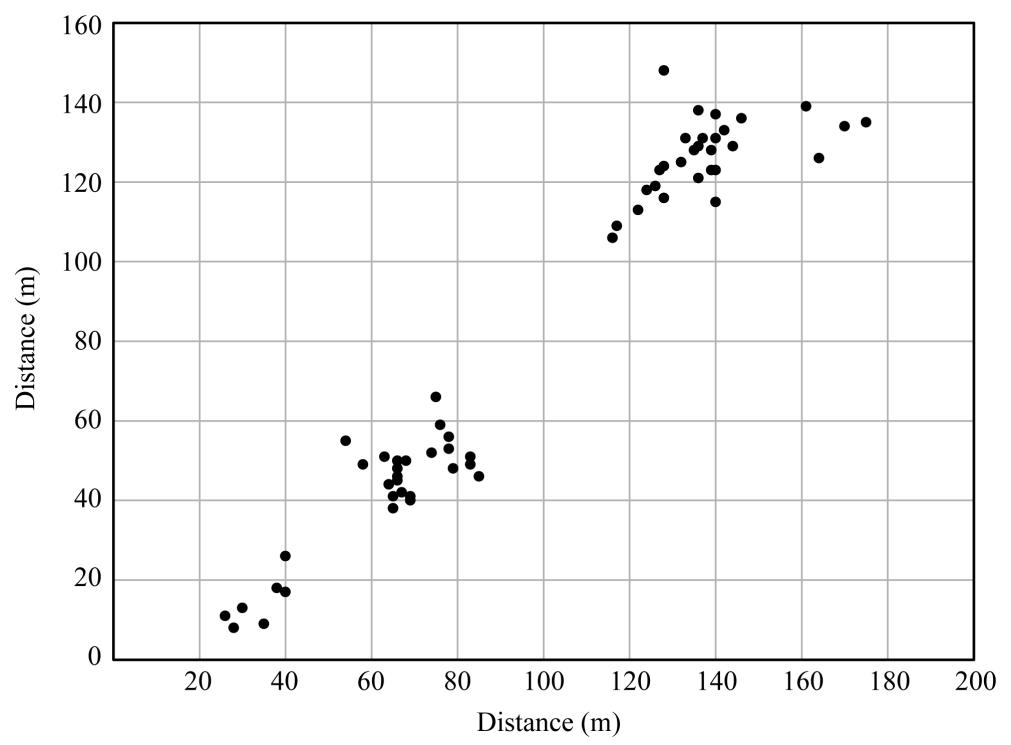

Figure S1. Spatial distribution of 60 adult plants of Pogonia ophioglossoides within the population sampled in Texas. A seedling was also sampled from near each adult that was sampled. 


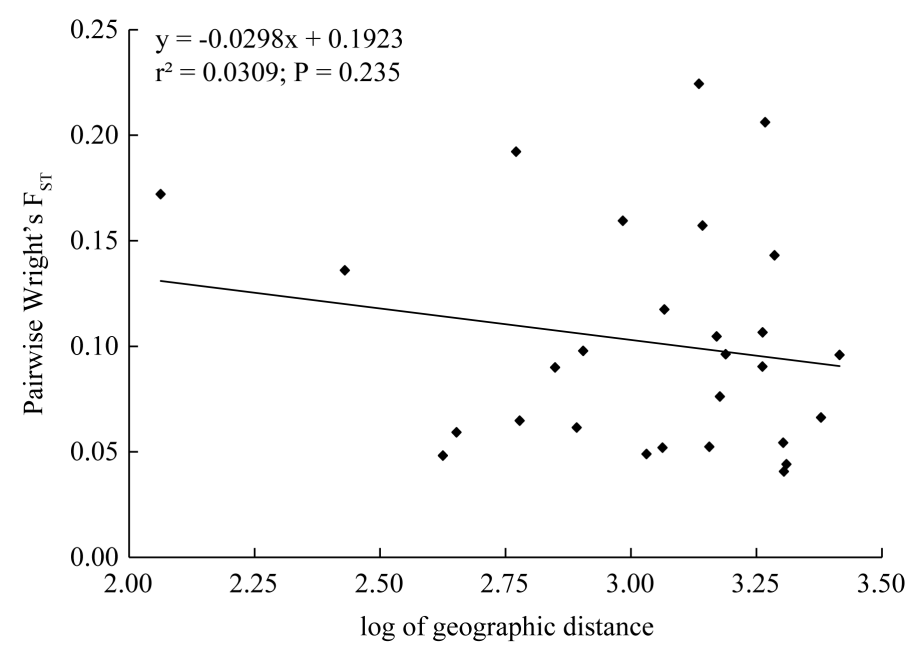

(a)

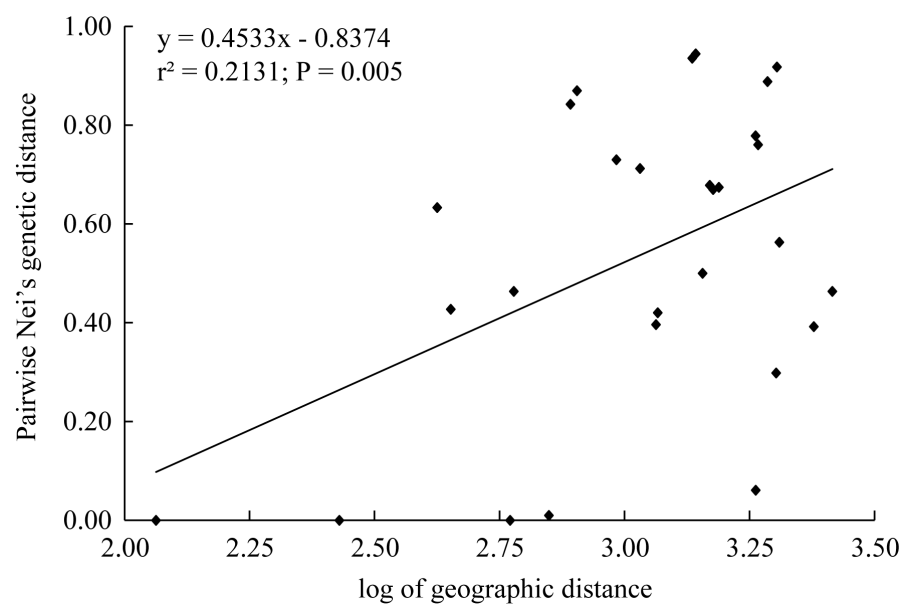

(b)

Figure S2. Correlation analysis of pair-wise log of geographic distances and pair-wise Wright's [42] $\mathrm{F}_{\mathrm{ST}}$ of the eight populations of Pogonia ophioglossoides based on three nDNA SSRs (a) or [41] genetic distances based on two cpDNA SSRs (b), for eight populations of Pogonia ophioglossoides. Correlation coefficient $\left(r^{2}\right)$ was calculated by using the Mantel test and the $\mathrm{P}$ values were estimated based on 9999 replications.

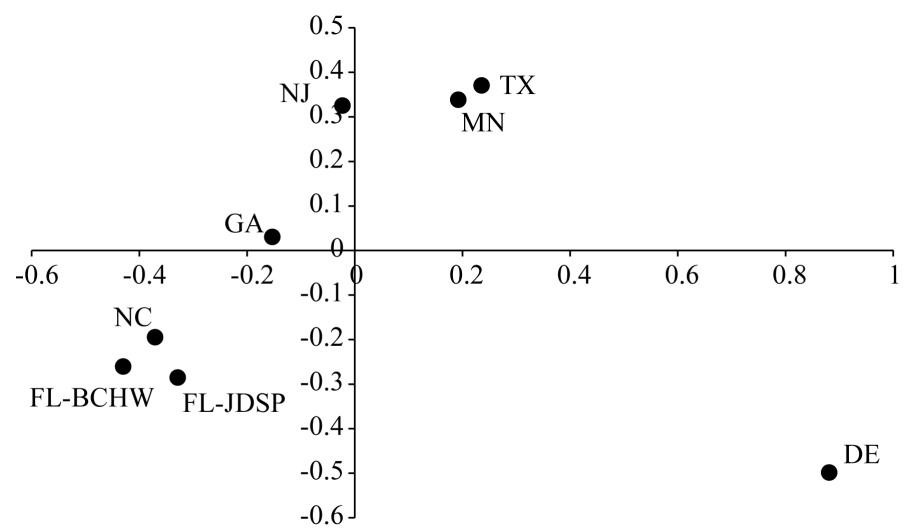

Figure S3. Principal Component Analysis of genetic variation across eight populations of Pogonia ophioglossoides based on three nDNA SSR markers. The percentage of inertia for the first and second coordinates were $39 \%(P=0.075)$ and $24 \%$ $(\mathrm{P}=0.116)$, respectively. 


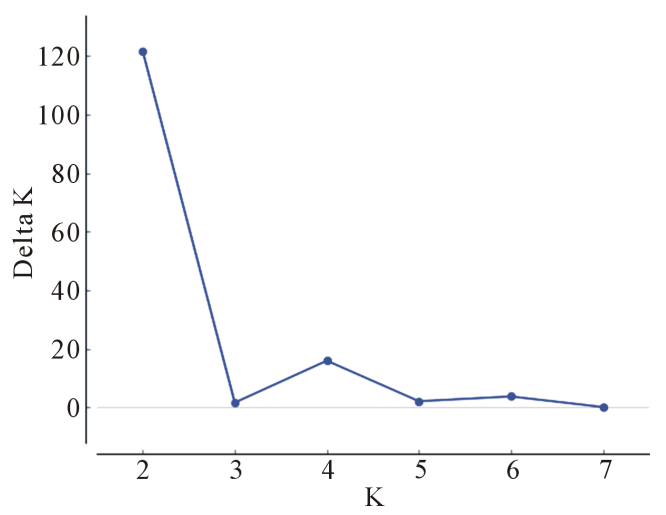

(1)

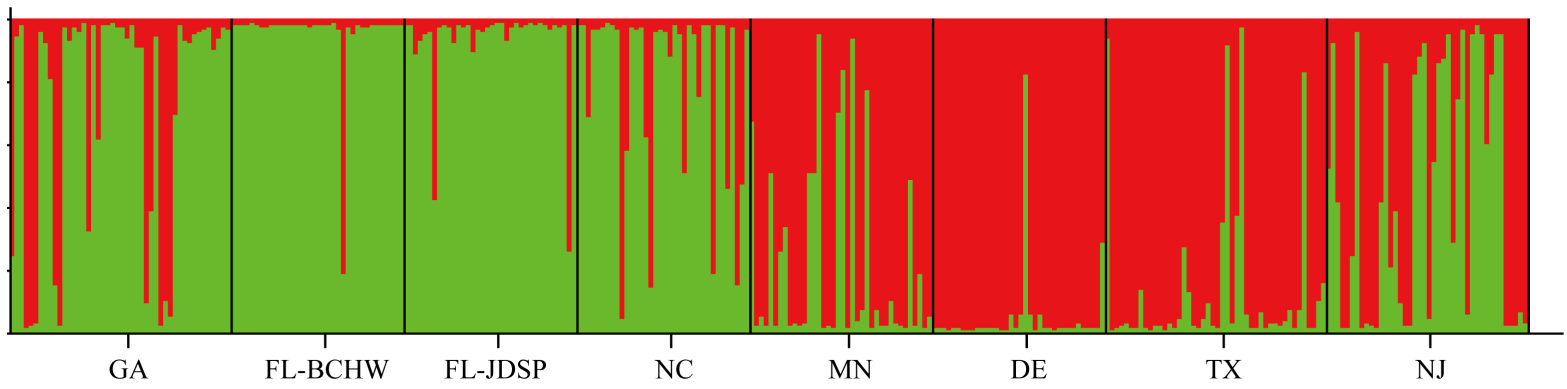

(2)

(a)

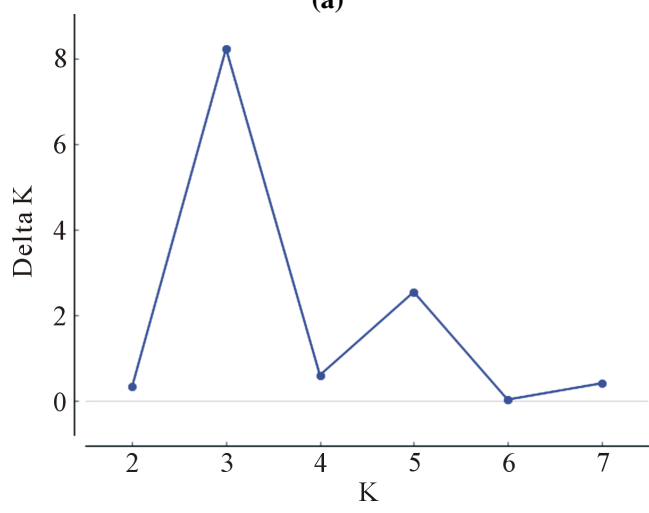

(1)

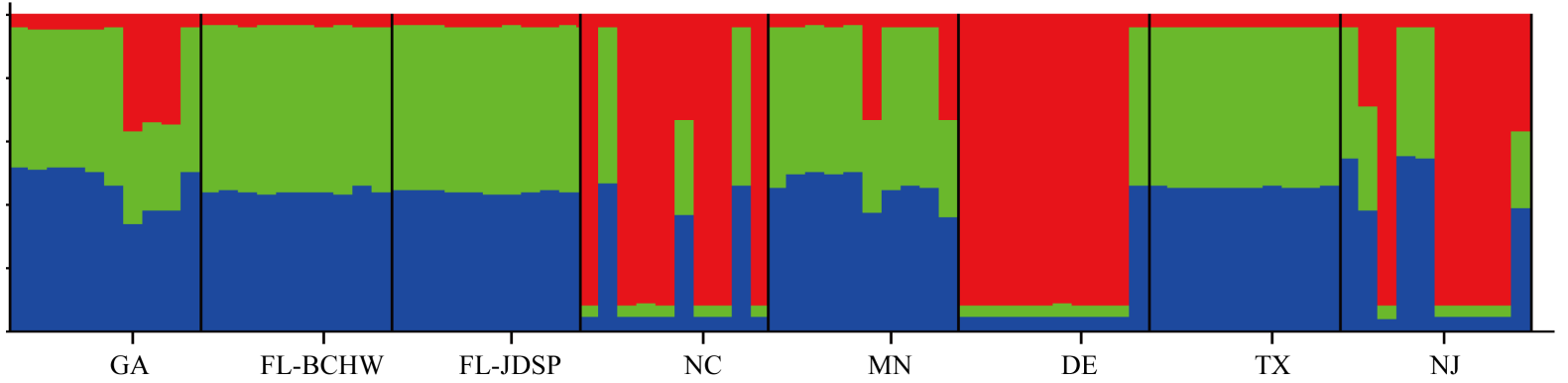

(2)

(b)

Figure S4. STUCTURE analysis of eight populations of Pogonia ophioglossoides based on three nuclear ((a(1)) and (a(2))) and two chloroplast microsatellites $(\mathbf{( b}(\mathbf{1}))$ and $(\mathbf{b}(2))) . \mathrm{K}=2$ and 3 appeared to be the optimal number of clusters by showing the $\Delta \mathrm{K}$ at its peak for nuclear $\mathbf{( a ( 1 ) )}$ and cpDNA microsatellites $(\mathbf{b}(\mathbf{1}))$, respectively. Colors in the bar graphs represent the number of clusters. 